\title{
EFFECT OF PERIPHERY FIXITY ON BALLISTIC LIMIT OF THIN ALUMINUM PLATE SUBJECTED TO BLUNT AND OGIVAL PROJECTILE IMPACT
}

\author{
G. TIWARI*, M.A. IQBAL and P.K. GUPTA \\ Department of Civil Engineering \\ Indian Institute of Technology Roorkee \\ Roorkee-247667, INDIA \\ E-mail: gauraviitdelhi@gmail.com
}

\begin{abstract}
Three-dimensional numerical simulations were carried out with the ABAQUS/explicit finite element code to study the influence of target boundary conditions on its ballistic limit. $1 \mathrm{~mm}$ thick 1100-H12 aluminum target of $255 \mathrm{~mm}$ span diameter was hit by $19 \mathrm{~mm}$ diameter and $50.8 \mathrm{~mm}$ length blunt nosed projectile. The mass of the projectile was kept as $52.5 \mathrm{gm}$. The boundary condition effects on the ballistic limit were investigated by varying the target periphery boundary condition as fully clamped and partially clamped target $(75 \%, 50 \%$ and $25 \%)$ subjected to projectile impact. The energy absorption and ballistic limit of the target was found to be significantly affected by the boundary conditions. Some of the finite element analysis results were compared with experimental and numerical results reported in international literature and a good agreement between the two was found.
\end{abstract}

Key words: periphery fixity, blunt nosed projectile, ABAQUS.

\section{Introduction}

The field of impact dynamics covers a large range of applications in different disciplines, e.g., production engineers are interested in blanking and punching operations, military scientists are interested in the design of armoured vehicles, vehicle manufacturers are interested in the performance and safety of structures subjected to impact loading.

The design of metal shields for protection against projectile impact has long been of interest in military and civilian applications. Penetration and perforation related problems have been studied for a long time, and substantial efforts have been made by experimental, numerical and theoretical investigations in order to understand the phenomena occurring in the target impacted by a projectile.

The influence of the nose shape, target thickness, angle of incidence, span and configuration on ballistic resistance of steel as well as aluminum has been studied in literature vastly. The failure mode of target struck by a blunt nosed projectile (Børvik et al., 2001; 2002; Gupta et al., 2006; Arias et al., 2008; Børvik et al., 2009; Dean et al., 2009), hemispherical projectile (Børvik et al., 2002; Gupta et al., 2006; 2007; Arias et al., 2008) and ogive nosed projectile (Gupta et al., 2007; Iqbal et al., 2010; 2010a; 2012) has been investigated.

The effect of the nose shape on the ballistic limit was investigated experimentally as well as numerically by Børvik et al. (2002), Gupta et al. (2006; 2007), Iqbal et al. (2010a). Børvik et al. (2002) carried out the numerical and experimental study on the impact response of $12 \mathrm{~mm}$ thick weldox $460 \mathrm{E}$ steel targets struck by a blunt, hemispherical and conical nose shape projectile. In continuation to investigate the effect of the nose shape on an aluminum target Gupta et al. (2006) conducted experiments on aluminum plates of $1 \mathrm{~mm}$ thickness with blunt and hemispherical nose projectiles. The ballistic limit velocity was found to be higher for hemispherical projectiles than that for blunt projectiles. In extension of the previous study Gupta et al. (2007) varied the nose shape of projectile hit on the different target thicknesses. The projectile

\footnotetext{
* To whom correspondence should be addressed
} 
nose shape was varied as blunt, ogive and hemispherical while the thickness of the aluminum target plate was varied as $0.5,0.71,1,1.5,2,2.5$ and $3 \mathrm{~mm}$. For plates of thicknesses $0.5,0.71,1.0$ and $1.5 \mathrm{~mm}$ ogive nosed projectiles were found to be the most efficient penetrators whereas for $2.0,2.5$ and $3.0 \mathrm{~mm}$ plate thicknesses blunt nosed projectiles required least energy for perforation. The hemispherical nosed projectiles were found to be least efficient projectiles for all the target thicknesses. Iqbal et al. (2010) varied the internal nose angle of $20 \mathrm{~mm}$ diameter conical projectile which was hit on steel targets was varied $\left(33.4^{\circ}-180^{\circ}\right)$ and the caliber radius head $(\mathrm{CRH})$ of $19 \mathrm{~mm}$ ogive nosed projectile which hit aluminum target was varied (0-2.5). It was found that a decrease in the projectile nose angle causes an increase in the ballistic limit of steel target. While the ballistic limit of an aluminum target increased as the CRH increased from 0 to 0.5 and with a further increase in CRH to 1.0, 1.5, 2.0 and 2.5 it decreases. Rusinek et al. (2008) reported a numerical study on a thin steel plate subjected to conical projectiles for which the diameter was varied keeping the mass constant. A linear increase of the ballistic limit was observed with the projectile diameter. Arias et al. (2008) carried out a numerical study of normal perforation of thin steel plates impacted by blunt, conical and hemispherical nosed projectiles. The failure mode for the blunt nose shape was observed as an adiabatic shear band propagation inducing plug ejection. For conical projectiles it was observed as a hole enlargement. Borvik et al. (2009) performed an experimental study on perforation of AA5083-H116 aluminum plates with varying thicknesses (between 15 and $30 \mathrm{~mm}$ ) struck by conical-nose hardened steel projectiles. The experimental results are finally compared to similar experiments on steel and concrete targets, and the capacity of the different materials is evaluated in relation to total weight. Dean et al. (2009) studied the impact phenomenon of thin $(0.4 \mathrm{~mm})$ steel plates impacted by spherical projectiles of hardened steel. At velocities close to the ballistic limit, the plates fail by dishing and discing. As the incident velocity is increased, the target failed due to shear plugging, fragmentation and petalling.

Iqbal et al. (2010) carried out a three-dimensional numerical study on the impact response of Weldox $460 \mathrm{E}$ steel as well as $1100-\mathrm{H} 12$ aluminum subjected to sharp nosed projectiles impact. It was concluded that monolithic targets were most efficient followed by layered in-contact targets of equivalent thickness. The aluminum target subjected to the ogive nosed projectile impact failed through petal formation while conical nosed projectile failed $12 \mathrm{~mm}$ thick steel target through a circular or elliptical hole enclosed by a bulge at the rear surface. Iqbal et al. (2012) studied the effect of span and configuration on the ballistic limit of a thin aluminum plate subjected to ogival and blunt nosed projectiles. The highest ballistic limit was observed for the monolithic target followed by layered in-contact and spaced targets, respectively. The ballistic limit was found to increase with an increase in the target span diameter for both the projectiles.

The subject of influence of projectile nose shape on the ballistic limit has been studied in literature by varying the projectile nose on different target configurations. However, there is a disagreement in the studies regarding the influence of projectile nose shape. On the other hand, there is hardly any study wherein the influence of the target periphery boundary conditions has been varied to understand its effect on the ballistic limit. The influence of projectile nose shape on target boundary conditions is also not clear and requires more investigation. The present numerical study describes the effect of boundary conditions and projectile nose shape on the ballistic limit. $1 \mathrm{~mm}$ thick monolithic 1100-H12 aluminum targets of span diameters $255 \mathrm{~mm}$ with varying boundary conditions were impacted by blunt and ogive nosed projectiles to obtain the ballistic limit. To study the influence of boundary conditions, impact velocities of projectiles were kept identical to those obtained during experiments carried out by Gupta et al. (2007). In general, the ballistic limit was found to increase with an increase in unclamped periphery region of target span.

\section{Numerical investigation}

This paper presents the numerical investigation of the influence of boundary conditions on the ballistic resistance of targets. The boundary conditions of the target plate were varied as $100 \%$ clamp, $75 \%$ clamp, $50 \%$ clamp and 25\% clamp as shown in Fig. 1 1100-H12 aluminum targets of $1 \mathrm{~mm}$ thickness were impacted by blunt and ogive nosed projectiles of $19 \mathrm{~mm}$ diameter, $50.8 \mathrm{~mm}$ length and 52.5 grams mass. A three-dimensional finite element model of the projectile and target was made using ABAQUS/CAE. Figure 2 shows a typical finite element model of the projectile and target. The projectile was modeled as a rigid body 
and the target was modeled as a deformable body. The contact between the projectile and target was modeled using the kinematic contact algorithm of ABAQUS-6.7-3 (2007). This algorithm is based on conservation of momentum and coefficient of restitution. It incorporates a novel method for handling potential voids and overlaps at contact intersection. The outer surface of the projectile was modeled as the master surface and the contact region of the target as a node based slave surface. Due to small target thickness frictional effects were not considered between the target and the projectile. The geometry, length $(50.8 \mathrm{~mm})$, mass $(52.5$ grams $)$ and diameter $(19 \mathrm{~mm})$ of blunt and ogive nosed projectiles were kept identical to those of the projectiles used by Gupta et al. (2007). The target was restrained at its periphery with respect to all degrees of freedom, but the region of clamped periphery was varied as $100 \%, 75 \%, 50 \%$ and $25 \%$. Eight node brick elements (C3D8R) were used in all the simulations carried out in this study.
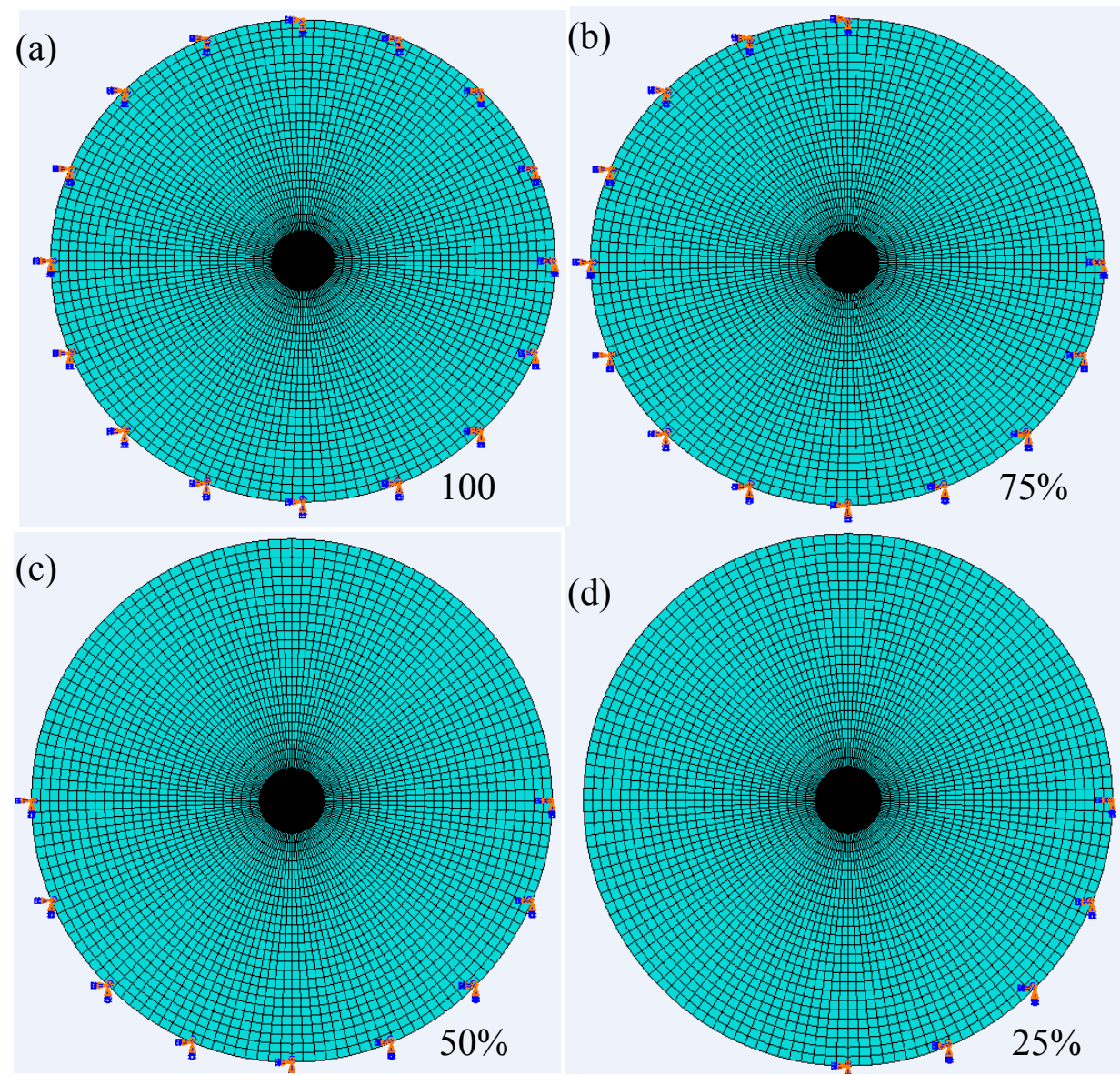

Fig.1. Variation in boundary conditions (a) $100 \%$ clamp (b) $75 \%$ clamp (c) $50 \%$ clamp (d) $25 \%$ clamp.
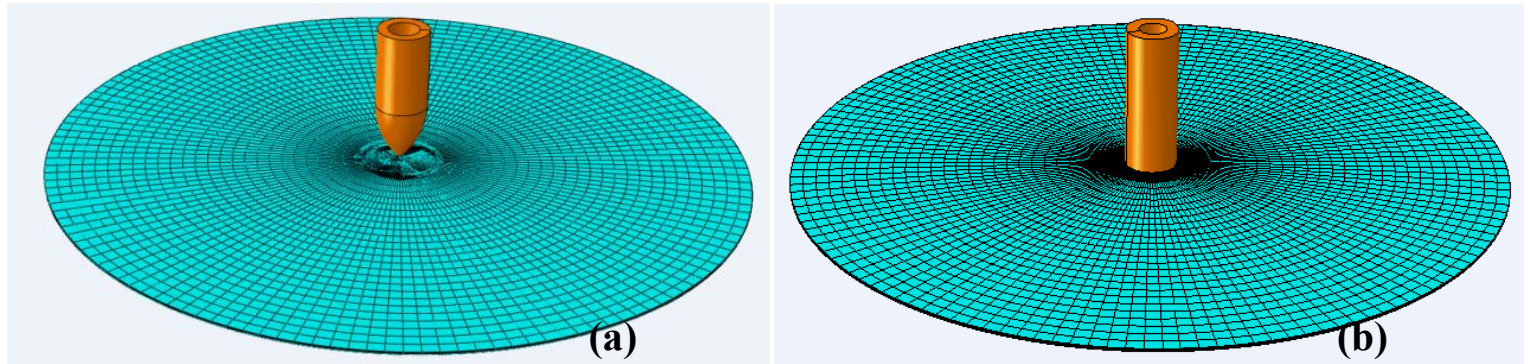

Fig.2. Finite element modelling of plate (a) for ogive nosed projectile impact (b) for blunt nosed projectile impact. 
Because of large deformation of the target, the mesh was highly refined and the aspect ratio was kept unity in the primary impact zone. A mesh convergence study (Iqbal et al., 2012) was carried out wherein the size of element in the $1 \mathrm{~mm}$ thick monolithic target was varied by varying the number of elements over thickness from 3 to 7 . The target was impacted at each mesh configuration by the ogive nosed projectile keeping constant impact velocity as $64.46 \mathrm{~m} / \mathrm{s}$. Thus the target was meshed with five different configurations taking the element edge length $0.33 \mathrm{~mm}, 0.25 \mathrm{~mm}, 0.20 \mathrm{~mm}, 0.16 \mathrm{~mm}$ and 0.144 $\mathrm{mm}$ corresponding to $3,4,5,6$ and 7 elements respectively. The residual velocities of the projectile were observed as $17.92 \mathrm{~m} / \mathrm{s}, 28.14 \mathrm{~m} / \mathrm{s}, 29.4 \mathrm{~m} / \mathrm{s}, 32.19 \mathrm{~m} / \mathrm{s}$ and $32.41 \mathrm{~m} / \mathrm{s}$ corresponding to $3,4,5,6$ and 7 elements respectively. It was found that the velocity drop of the projectile decreased up to 5 elements and afterward it became almost constant. It was therefore decided to mesh the monolithic target with 6 elements across the thickness.

\section{Constitutive model}

The mechanics of a material subjected to projectile impact is found to be very complex. It includes the effect of linear thermo-elasticity, yielding, plastic flow, isotropic strain hardening, strain rate hardening, softening due to adiabatic heating and damage. The material behavior of 1100-H12 aluminum target was incorporated in the numerical simulations using Johnson-Cook elasto-viscoplastic material model (Johnson and Cook, 1983; 1985). The equivalent von-Mises stress $\bar{\sigma}$ of the Johnson-Cook model is expressed as

$$
\bar{\sigma}\left(\bar{\varepsilon}^{p l}, \dot{\bar{\varepsilon}}^{p l}, \hat{T}\right)=\left[A+B\left(\bar{\varepsilon}^{p l}\right)^{n}\right]\left[1+C \ln \left(\frac{\dot{\bar{\varepsilon}}^{p l}}{\dot{\varepsilon}_{0}}\right)\right]\left[1-\hat{T}^{m}\right]
$$

where $A, B, n, C$ and $m$ are material parameters. $\bar{\varepsilon}^{p l}$ is the equivalent plastic strain, $\dot{\bar{\varepsilon}}^{p l}$ is the equivalent plastic strain rate, $\dot{\varepsilon}_{0}$ is the reference strain rate and $\hat{T}$ is the non dimensional temperature defined as

$$
\hat{T}=\left(T-T_{0}\right) /\left(T_{\text {melt }}-T_{0}\right), \quad T_{0} \leq T \leq T_{\text {melt }}
$$

where $T$ is the current temperature, $T_{\text {melt }}$ is the melting temperature and $T_{0}$ is the room temperature. The fracture model proposed by Johnson-Cook (1983) takes into account the effect of stress triaxiality, strain rate and temperature on the equivalent fracture strain. The equivalent fracture strain $\bar{\varepsilon}_{f}^{p l}$ is expressed as

$$
\bar{\varepsilon}_{f}^{p l}\left(\frac{\sigma_{m}}{\bar{\sigma}}, \dot{\bar{\varepsilon}}^{p l}, \hat{T}\right)=\left[D_{1}+D_{2} \exp \left(D_{3} \frac{\sigma_{m}}{\bar{\sigma}}\right)\right]\left[1+D_{4} \ln \left(\frac{\dot{\bar{\varepsilon}}^{p l}}{\dot{\varepsilon}_{0}}\right)\right]\left[1+D_{5} \hat{T}\right]
$$

where $D_{1}-D_{5}$ are material parameters, $\frac{\sigma_{m}}{\bar{\sigma}}$ is the stress triaxiality ratio and $\sigma_{m}$ is the mean stress. The material parameters used in the present investigation are given in Tab.1. 
Table 1. Material parameters for 1100-H12 aluminum target used in numerical simulations.

\begin{tabular}{|l|l|}
\hline Modulus of Elasticity, E $\left(\mathrm{N} / \mathrm{mm}^{2}\right)$ & 65762 \\
\hline Poison's ratio, $v$ & 0.3 \\
\hline Density, $\rho\left(\mathrm{kg} / \mathrm{m}^{3}\right)$ & 2700 \\
\hline Yield stress, $A\left(\mathrm{~N} / \mathrm{mm}^{2}\right)$ & 148.361 \\
\hline$B\left(\mathrm{~N} / \mathrm{mm}^{2}\right)$ & 345.513 \\
\hline$n$ & 0.183 \\
\hline Reference strain rate, $\dot{\varepsilon}_{0}\left(\mathrm{~s}^{-1}\right)$ & 1.0 \\
\hline$C$ & 0.001 \\
\hline$m$ & 0.859 \\
\hline$T_{\text {melt }}(K)$ & 893 \\
\hline$T_{0}(K)$ & 293 \\
\hline Specific heat, $C_{p}(\mathrm{~J} / \mathrm{kg}-K)$ & 920 \\
\hline Inelastic heat fraction, $\alpha$ & 0.9 \\
\hline$D_{1}$ & 0.071 \\
\hline$D_{2}$ & 1.248 \\
\hline$D_{3}$ & -1.142 \\
\hline$D_{4}$ & 0.0097 \\
\hline$D_{5}$ & 0.0 \\
\hline
\end{tabular}

\section{Results and discussion}

The results of the present numerical study for varying target boundary conditions are shown in Tabs 2 and 3 in the form of impact and residual velocities of ogive and blunt nosed projectiles respectively. Each projectile was impacted normally on $1 \mathrm{~mm}$ thick and $255 \mathrm{~mm}$ span diameter targets which were $100 \%, 75 \%$, $50 \%$ and $25 \%$ clamped at its periphery. The fully clamp target offered least resistance for projectile perforation among all the boundary conditions cases studied. As the unclamped region at periphery increases the ballistic resistance increases due to an increase in the plastic deformation of the target plate. The target plate deforms locally as well as globally, specially in a partially clamped target plate. Besides it, some energy is absorbed in vibration of unclamped zone of the target plate. At low velocity, the global deformation of the target plate was found to be more significant.

Even the target plate is folded with perforation of both the projectile especially for $25 \%$ and $50 \%$ clamped target. Due to a large deformation of the unclamped portion, the ballistic limit also increases. Due to an uneven plastic deformation of the partially clamped target the projectile deviates slightly from its original path after perforation. This phenomenon becomes more significant at low velocity.

Table 2 shows the effect of boundary conditions on the ballistic resistance of the plate struck by ogive nosed projectiles in terms of impact velocity and residual velocity. A significant decrease in residual velocity was found with an increase in the unclamped periphery zone. A similar effect can be seen for blunt nosed projectile impact in Tab.3. A numerical model was found to be stiffer which causes lower residual velocity compared to experimental results. The experimental and axisymmetric numerical simulation results reported by Gupta et al. (2007) are also tabulated. The effect of boundary conditions is 
more significant for blunt nosed projectile impact. Table 4 shows the ballistic limit for ogive as well as blunt nosed projectiles.

Table 2. Experimental and numerical results for varying boundary conditions of $1 \mathrm{~mm}$ thick target impacted by ogive nosed projectile.

\begin{tabular}{|c|c|c|c|c|c|c|}
\hline & & $\begin{array}{l}\text { Target Thic } \\
\text { ive Nosed Proje }\end{array}$ & $\begin{array}{l}\text { ness }=1 \mathrm{~mm} \text {, Spa } \\
\text { ile of (Mass }=52\end{array}$ & $\begin{array}{l}\text { Diameter }=255 \\
\text { grams, Diamete }\end{array}$ & $\stackrel{l m}{=19 \mathrm{~mm})}$ & \\
\hline $\begin{array}{l}\text { Experime } \\
\text { Gupta et }\end{array}$ & $\begin{array}{l}\text { results } \\
(2007)\end{array}$ & $\begin{array}{l}\text { Axi-symmetric } \\
\text { numerical } \\
\text { results }\end{array}$ & & Numerical result & of present study & \\
\hline & & & $100 \%$ clamped & $75 \%$ clamped & $50 \%$ Clamped & $\begin{array}{c}25 \% \\
\text { Clamped }\end{array}$ \\
\hline $\begin{array}{c}\text { Impact } \\
\text { Velocity } \\
V i(\mathrm{~m} / \mathrm{s})\end{array}$ & & & Residual Ve & ocity $\operatorname{Vr}(\mathrm{m} / \mathrm{s})$ & & \\
\hline 112.72 & 99.11 & 95.64 & 95.36 & 95.40 & 94.38 & 94.85 \\
\hline 97.23 & 78.26 & 73.26 & 77.32 & 76.56 & 76.08 & 76.15 \\
\hline 82.97 & 61.62 & 55.71 & 58.95 & 58.95 & 58.29 & 57.97 \\
\hline 81.91 & 58.19 & 53.28 & 57.64 & 57.04 & 56.90 & 56.44 \\
\hline 73.3 & 44.38 & 38.68 & 44.5 & 44.20 & 43.74 & 42.35 \\
\hline 70 & - & - & - & - & - & 33.41 \\
\hline 65.8 & 29.68 & 26.04 & 26.65 & 22.79 & 12.86 & 0 \\
\hline 64.25 & - & - & - & 9.3 & 0 & - \\
\hline 60 & - & - & 2.05 & 0 & - & - \\
\hline 57.28 & 17.87 & 15.93 & 0 & - & - & - \\
\hline 52.1 & - & 0 & - & - & - & - \\
\hline 51.28 & 8.27 & - & - & - & - & - \\
\hline
\end{tabular}


Table 3. Experimental and numerical results for varying boundary conditions of $1 \mathrm{~mm}$ thick target impacted by blunt nosed projectile.

\begin{tabular}{|c|c|c|c|c|c|c|}
\hline & & $\begin{array}{l}\text { Target Thick } \\
\text { nt Nosed Project }\end{array}$ & $\begin{array}{l}=1 \mathrm{~mm}, \mathrm{~s} \\
\mathrm{f}(\mathrm{Mass}=\end{array}$ & $\begin{array}{l}\text { Diameter }=255 \\
\text { grams, Diamete }\end{array}$ & $\begin{array}{l}\mathrm{nm} \\
=19 \mathrm{~mm})\end{array}$ & \\
\hline $\begin{array}{r}\text { Experime } \\
\text { Gupta } e t\end{array}$ & $\begin{array}{l}\text { Results } \\
(2007)\end{array}$ & $\begin{array}{c}\text { Axi-symmetric } \\
\text { Numerical } \\
\text { Results } \\
\text { Gupta et al. }\end{array}$ & & Numerical Resul & s of Present Stud & \\
\hline & & & $\begin{array}{c}100 \% \\
\text { Clamped }\end{array}$ & $75 \%$ Clamped & $50 \%$ Clamped & $\begin{array}{c}25 \% \\
\text { Clamped }\end{array}$ \\
\hline $\begin{array}{c}\text { Impact } \\
\text { Velocity } \\
V i(\mathrm{~m} / \mathrm{s}) \\
\end{array}$ & & & Residual & locity $\operatorname{Vr}(\mathrm{m} / \mathrm{s})$ & & \\
\hline 115.6 & 92.98 & 98.66 & 91.25 & 90.91 & 90.39 & 90.26 \\
\hline 104.03 & 80.17 & 83.91 & 75.69 & 74.88 & 73.96 & 73.52 \\
\hline 102.5 & 79.16 & 82.51 & 72.81 & 72.35 & 71.37 & 70.7 \\
\hline 92.45 & 67.45 & 63.30 & 57.6 & 58.06 & 52.46 & 50.6 \\
\hline 87.45 & 58.26 & 53.15 & 46.6 & 41.75 & 35.41 & 32.56 \\
\hline 85.61 & - & - & - & 35.99 & 15.7 & 22.86 \\
\hline 85 & - & - & - & - & 5.8 & 13.2 \\
\hline 84.5 & - & - & - & - & - & 4.3 \\
\hline 84.0 & - & - & - & 27.43 & 0 & 0 \\
\hline 83.0 & - & - & - & - & & \\
\hline 82.0 & - & - & - & 7.19 & & \\
\hline 80.0 & - & - & 14.85 & 0 & & \\
\hline 78.8 & - & - & 3.5 & & & \\
\hline 78 & - & - & 0 & & & \\
\hline 73.98 & 43.84 & 40.64 & & & & \\
\hline 66.7 & - & 0 & & & & \\
\hline 61.3 & 0 & & & & & \\
\hline
\end{tabular}


Table 4. Ballistic limit of different configurations of $1 \mathrm{~mm}$ thick target.

\begin{tabular}{|c|c|c|}
\hline \multirow{2}{*}{ Target configuration } & \multicolumn{2}{|c|}{ Ballistic limit $\left(V_{50} \mathrm{~m} / \mathrm{s}\right)$} \\
\cline { 2 - 3 } & Ogive nosed projectile & Blunt nosed projectile \\
\hline $100 \%$ clamp & 58.64 & 79.00 \\
\hline $75 \%$ clamp & 62.12 & 81.00 \\
\hline $50 \%$ clamp & 65.03 & 84.50 \\
\hline $25 \%$ clamp & 67.90 & 84.25 \\
\hline
\end{tabular}

The ballistic limit is the velocity required for a particular projectile to penetrate a particular piece of material or a given projectile will not pierce a given target when the projectile velocity is lower than the ballistic limit. In the present study the ballistic limit was calculated as the average of the maximum velocity at which the projectile cannot penetrate the target material and minimum velocity at which the projectile completely penetrated the target material. In the case of ogive nosed projectiles the ballistic limit was found as $58.64,62.12,65.03$ and $67.90 \mathrm{~m} / \mathrm{s}$ for $100 \%$ clamp, $75 \%$ clamp, $50 \%$ clamp and $25 \%$ clamped target respectively. Whereas the same was found as $79.0,81,84.5$ and $84.25 \mathrm{~m} / \mathrm{s}$ for $100 \%$ clamp, $75 \%$ clamp, $50 \%$ clamp and $25 \%$ clamped target respectively. For each case the ballistic limit of ogive nosed projectiles was found to be higher compared to blunt nosed projectiles.

Figure 3 compares the results of the present numerical study with experiments and axi-symmetric numerical simulations carried out by Gupta et al. (2007) for $1 \mathrm{~mm}$ thick monolithic target of $255 \mathrm{~mm}$ span diameter. For ogive nosed projectiles the ballistic limit of target was found to be $58.64 \mathrm{~m} / \mathrm{s}$ from the present numerical study and $48.2 \mathrm{~m} / \mathrm{s}$ from the experiments. For blunt nosed projectiles the same was found to be $78.4 \mathrm{~m} / \mathrm{s}$ from the present numerical study and $67.6 \mathrm{~m} / \mathrm{s}$ from the experiments.

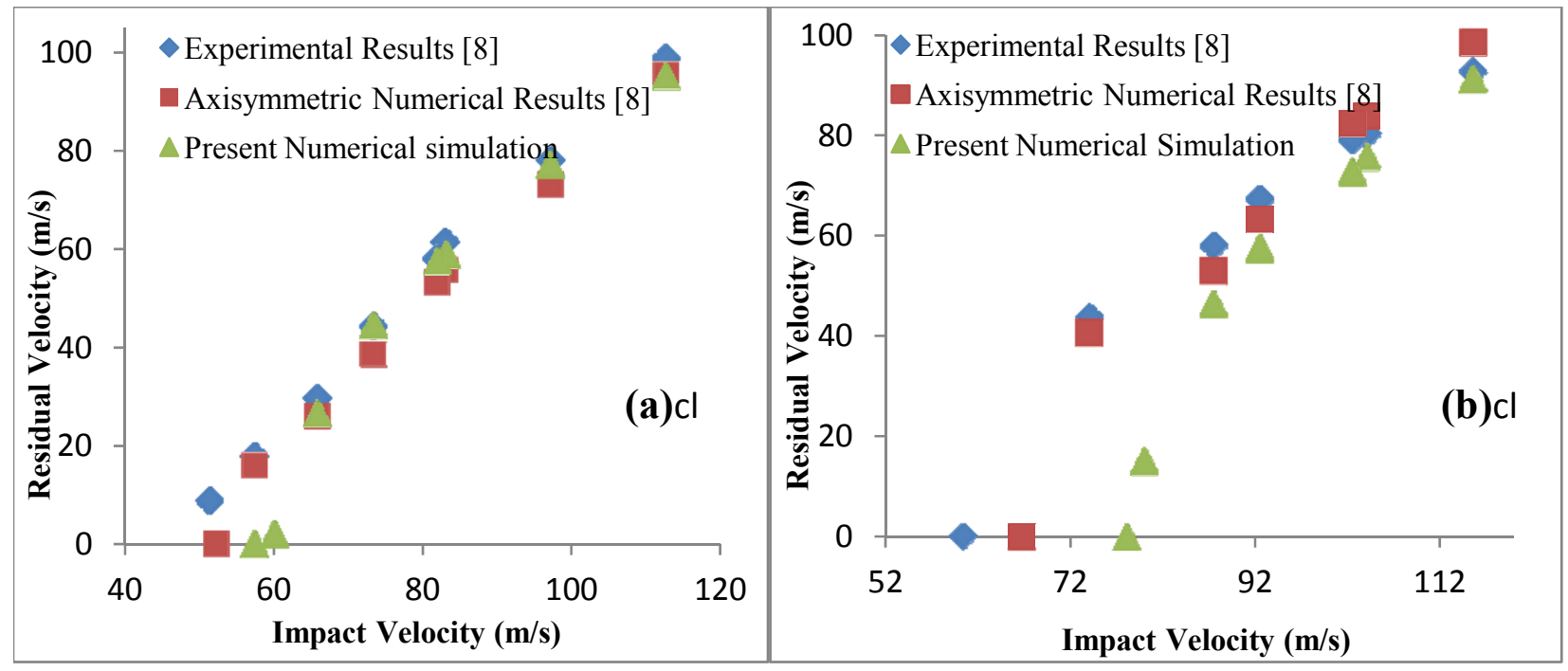

Fig.3. Comparison of present three-dimensional numerical simulation results with the experimental (Gupta et al., 2007) and axi-symmetric numerical studies (Gupta et al., 2007) for $1 \mathrm{~mm}$ thick 1100-H12 aluminum target impacted by (a) ogive nosed projectile; (b) blunt nosed projectile.

As the unclamped region at target periphery increases, the target resistance to projectile perforation decreases for both the projectiles. However, this effect was prominent in the case of blunt nosed projectile. Again, the increase in the ballistic limit with a reduction in the clamped periphery was more significant for blunt nosed projectiles.

Boundary conditions do not have any effect on the failure mode of a thin aluminum target. Figure $4 \mathrm{a}$ shows the failure mode of $1 \mathrm{~mm}$ thick $255 \mathrm{~mm}$ span diameter targets impacted by ogive nosed projectiles. 
The sharp nosed projectile impact caused failure through ductile hole enlargement and petal formation. Four equal petals were formed in the fully and partially clamped target. Petals were bent at $90^{\circ}$ from the surface of the target for each configuration. Experiments (Gupta et al., 2007) also revealed that four equal petals were formed in $1 \mathrm{~mm}$ thick target struck by ogive nosed projectiles. Figure $4 \mathrm{~b}$ shows the failure mode of $1 \mathrm{~mm}$ thick aluminum target struck by blunt nosed projectiles. The projectile failed the target with different boundary conditions by shear plugging. A clean cut circular hole was formed in the target which causes a circular plug removal from the parent target material. The thickness of the plug was found same as the parent target material and diameter of the plug was found same as the diameter of the projectile.
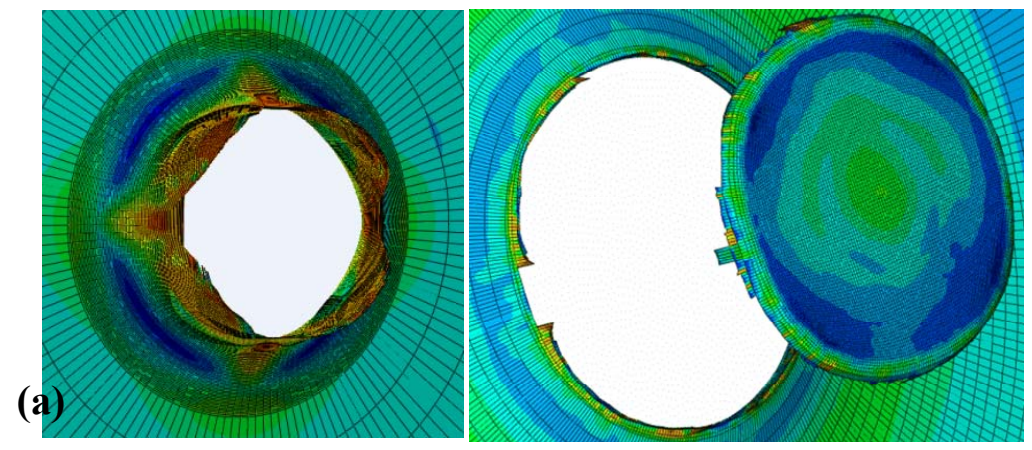

(b)

Fig.4. Fracture modes of $1 \mathrm{~mm}$ thick $255 \mathrm{~mm}$ span diameter target impacted by (a) ogive nosed projectile (b) blunt nosed projectile.

Figure 5 shows the perforation phenomenon of $1 \mathrm{~mm}$ thick $255 \mathrm{~mm}$ span diameter targets impacted by ogive and blunt nosed projectiles. The projectile nose played a critical role in the deformation as well as the fracture mode of the target. The phenomena of ductile hole enlargement and petal formation by ogive nosed projectiles can be seen, whereas the shearing of the target and removal of a clear circular plug by the blunt nosed projectile is also visible.

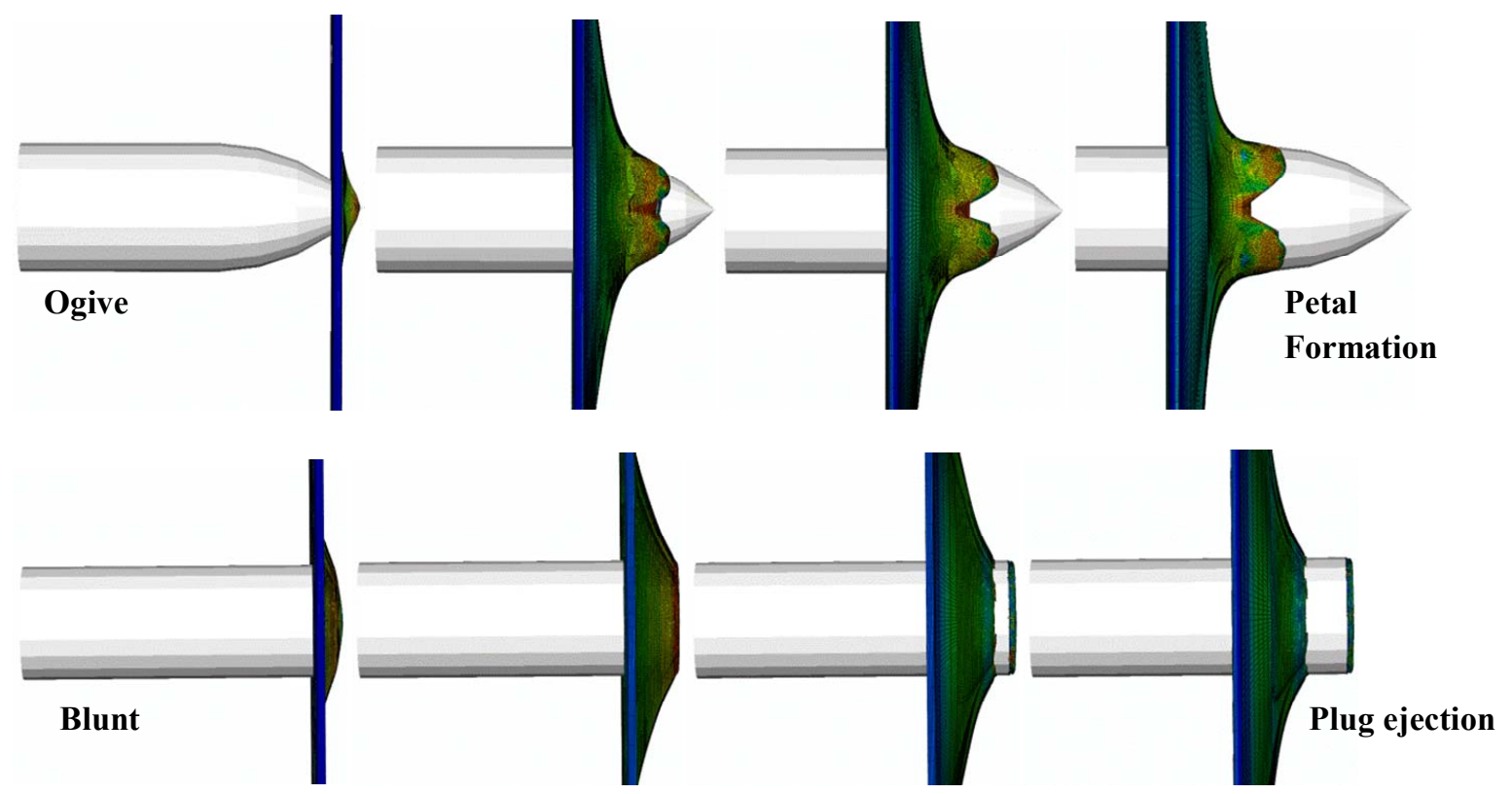

Fig.5. Perforation of $1 \mathrm{~mm}$ thick $255 \mathrm{~mm}$ span diameter target by ogive and blunt nosed projectiles. 
When the sharp nosed projectile hits the plate, an initial crack appears at the tip of the projectile due to compressive stresses. The cracks subsequently propagate outwards due to the pressure of the high velocity of the projectile. After a partial perforation, the nose of the projectile tends to enlarge the circumference of the initiated hole. The hoop stress is thus mainly responsible for further radial extension of the cracks. This crack propagation causes formation of petals and due to further movement of the projectile these petal bend in the rear direction as shown in Fig.5. Similarly, when blunt nosed projectile hit the target a narrow shear band appears around the blunt nosed projectile. In the thickness direction the behavior of stresses changes from compressive stresses, shear stresses and tensile stresses from front to rear side respectively. A clear circular plug whose diameter is the same as the projectile diameter and thickness equals the parent target metal separates from the target as shown in Fig.5.

Figures 6 and 7 show the von-Mises and axial displacement contours respectively for different boundary conditions target plate impacted by ogive nosed projectiles. For $100 \%$ clamp boundary conditions the axial displacements as well as von-Mises stress are distributed uniformly as shown in Figs 6a and 7a. The maximum axial displacement was observed at the centre of the target plate. For a partially clamped target, the plate deforms unevenly which cause more deformation in the unclamped periphery zone. The maximum axial displacement at the target periphery was observed as 32.4, 21.7, 11.0 and $0 \mathrm{~mm}$ for $25 \%, 50 \%, 75 \%$ and $100 \%$ clamped periphery target respectively struck by ogive nosed projectiles at the velocity of $65.8 \mathrm{~m} / \mathrm{s}$. Similar contour plots were observed for von-Mises stresses also. The maximum von-Mises stress was observed at the centre only for each case.
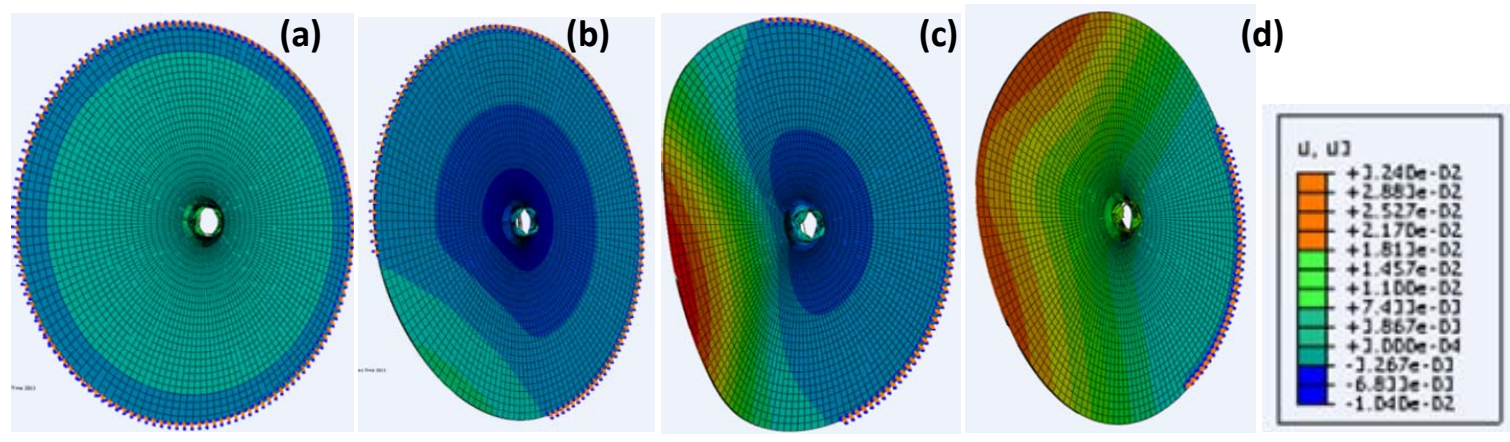

Fig.6. Contour plots for axial displacement for (a) $100 \%$ clamp (b) $75 \%$ clamp (c) $50 \%$ clamp (d) $25 \%$ clamp target plate at periphery impacted by ogive nosed projectile at $65.8 \mathrm{~m} / \mathrm{s}$ impact velocity.
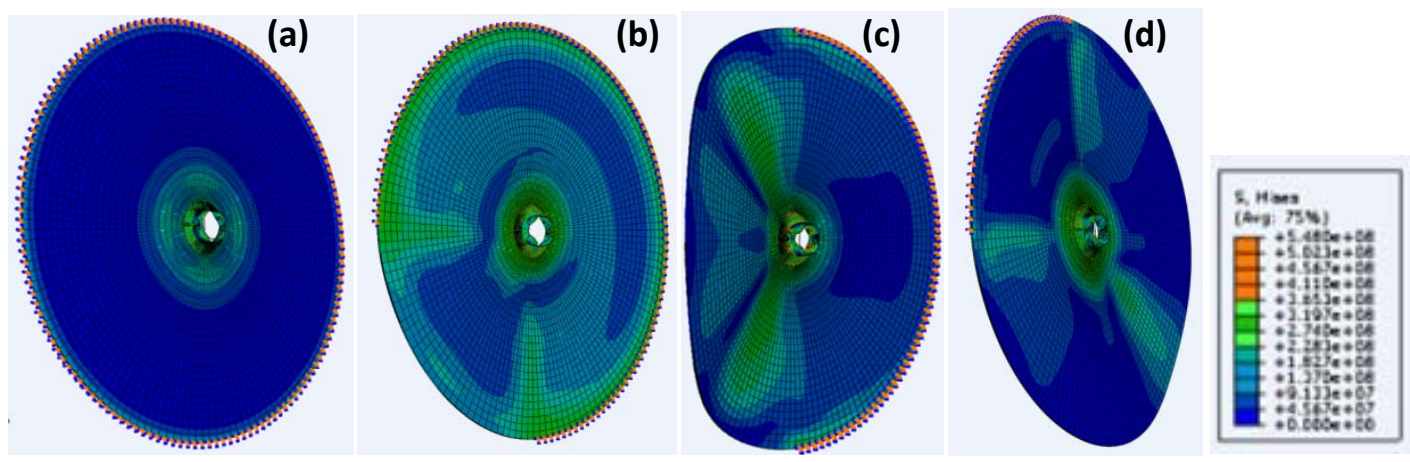

Fig.7. Contour plots for von-Mises stress for (a) $100 \%$ clamp (b) $75 \%$ clamp (c) $50 \%$ clamp (d) $25 \%$ clamp target plate at periphery impacted by ogive nosed projectile at $65.8 \mathrm{~m} / \mathrm{s}$ impact velocity.

A similar pattern of contour plots can be observed for axial displacement as well as von-Mises stress for the fully and partially clamped target subjected to blunt projectile impact as shown in Figs 8 and 9 . 

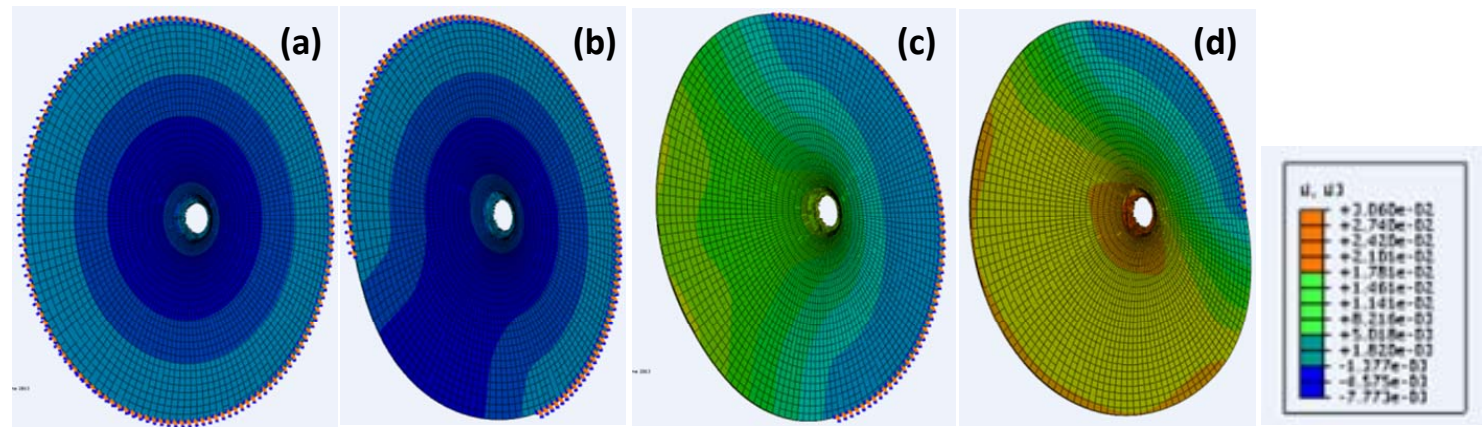

Fig.8. Contour plots for axial displacement for (a) $100 \%$ clamp (b) $75 \%$ clamp (c) $50 \%$ clamp (d) $25 \%$ clamp target plate at periphery impacted by blunt nosed projectile at $87.45 \mathrm{~m} / \mathrm{s}$ impact velocity.
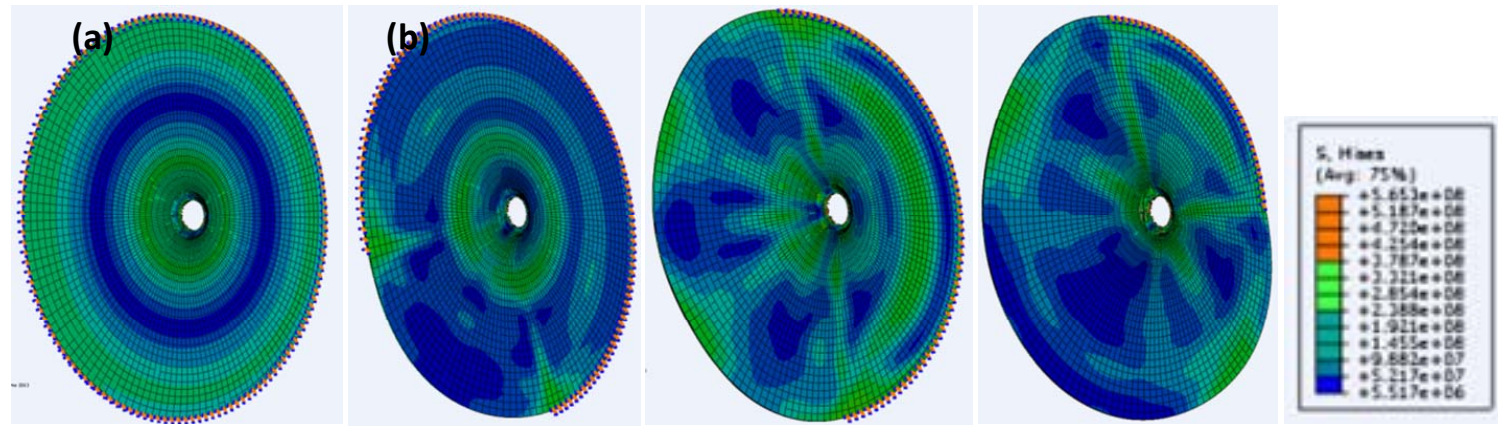

Fig.9. Contour plots for von-Mises stress for (a) $100 \%$ clamp (b) $75 \%$ clamp (c) $50 \%$ clamp (d) $25 \%$ clamp target plate at periphery impacted by blunt nosed projectile at $87.45 \mathrm{~m} / \mathrm{s}$ impact velocity.

The maximum axial displacement at the periphery was observed as $30.6,17.8,5$ and $0 \mathrm{~mm}$ for $25 \%$, $50 \%, 75 \%$ and $100 \%$ clamped periphery target respectively struck by blunt nosed projectiles at the velocity of $87.45 \mathrm{~m} / \mathrm{s}$. The unclamped periphery target created additional vibration because of less stiffness and large plastic deformations. The plastic deformation of the target increases with a decrease in the impact velocity. For $50 \%$ and $25 \%$ clamped boundary conditions, the beginning of the target folding was observed. Near the ballistic limit the folding phenomenon was more significant.

Figure 10 compares the impact response of the fully and partially clamped thin aluminum target struck by ogive and blunt nosed projectiles in the form of impact and residual velocity curves. For both the projectiles the ballistic limit of $100 \%$ clamped target was found to be highest followed by $75 \%$ clamped, $50 \%$ clamped and $25 \%$ clamped targets respectively. It was also observed that at higher velocities the difference in ballistic resistance of target subjected to blunt nosed projectile impact and ogival projectile impact is smaller. This difference increases as the impact velocity decreases and is found to be highest at its ballistic limit. For all the cases studied here, the blunt nosed projectile was found to be a better penetrator compared to an ogival projectile.

Figure 11 shows the effect of boundary condition on ballistic resistance of target plate in terms of impact and residual velocity. It was observed that as the clamp periphery region decreases the residual velocity decreases for both the projectile impact. For blunt projectile impact the difference between $50 \%$ clamped and $25 \%$ clamped target was smaller. 

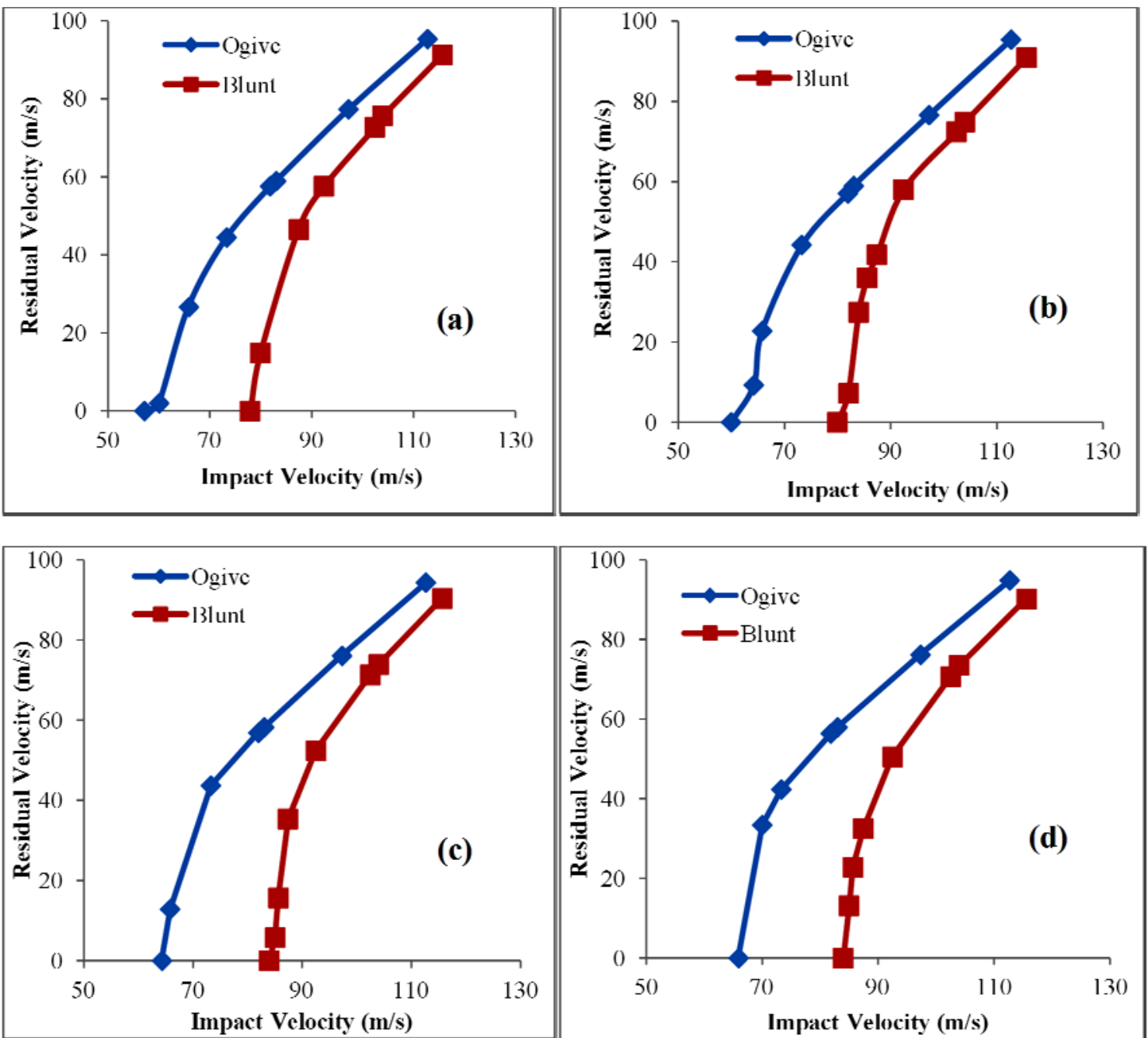

Fig.10. Comparison of impact and residual velocities of blunt and ogive nosed projectiles impacted on $1 \mathrm{~mm}$ thick monolithic target with (a) $100 \%$ clamp (b) $75 \%$ clamp (c) $50 \%$ clamp (d) $25 \%$ clamp.
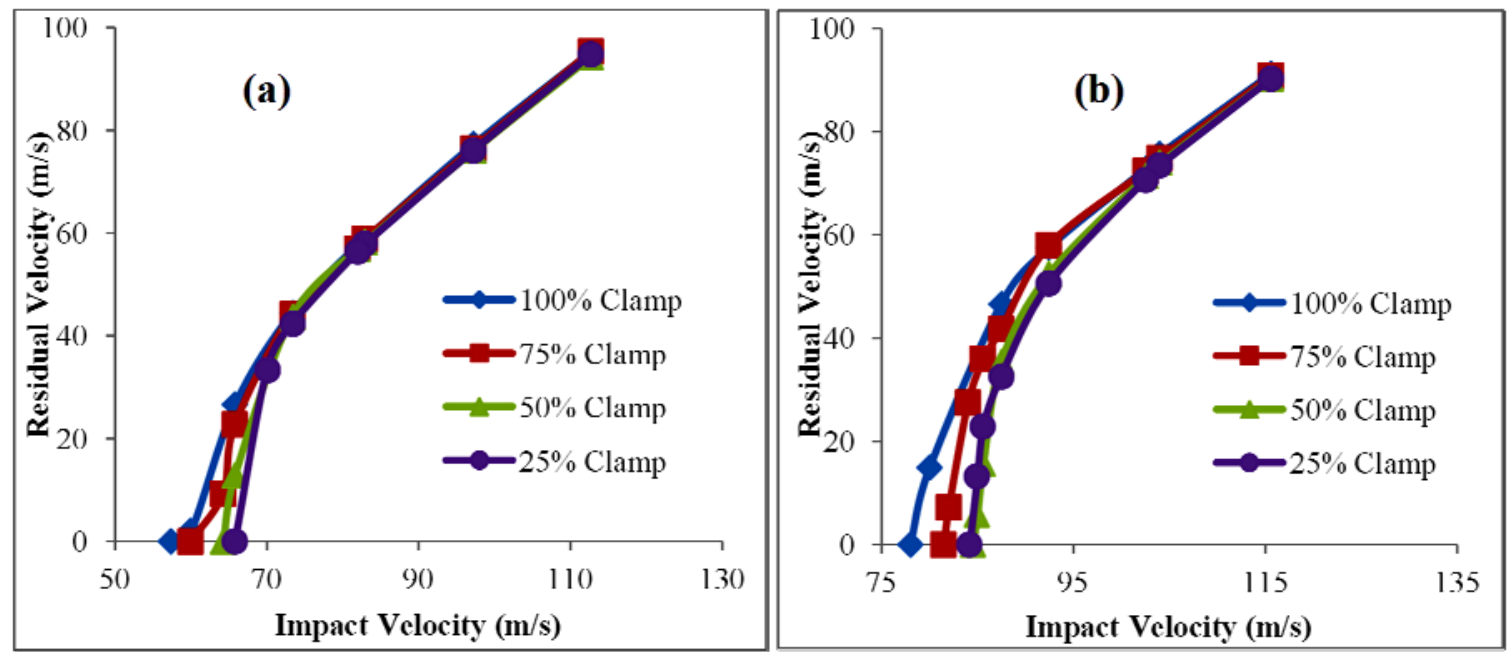

Fig.11. Variation in impact and residual velocities of different boundary conditions for (a) ogive nosed (b) blunt nosed projectile impact. 
Figure 12 shows the variation of ballistic limit with different boundary condition for ogival as well as blunt nosed projectile impact. It shows that as the unclamped target periphery zone increases the ballistic limit of the target plate increases. The reason behind this was again large plastic deformation of the unclamped zone. For all cases the ballistic limit of an ogive nosed projectile was found lower than for a blunt nosed projectile.

Figure 13 shows the comparison of velocity drop of ogival and blunt nosed projectiles. For each case the velocity drop is higher for ogival projectile compared to blunt nosed projectile. At higher impact velocity the velocity drop was the smallest. It was observed that as the impact velocity decreases the same increases and becomes highest at ballistic limit. Same behavior has been found for both the projectile impact. The difference in velocity drop between ogival and blunt projectile increases with decreases in impact velocity.

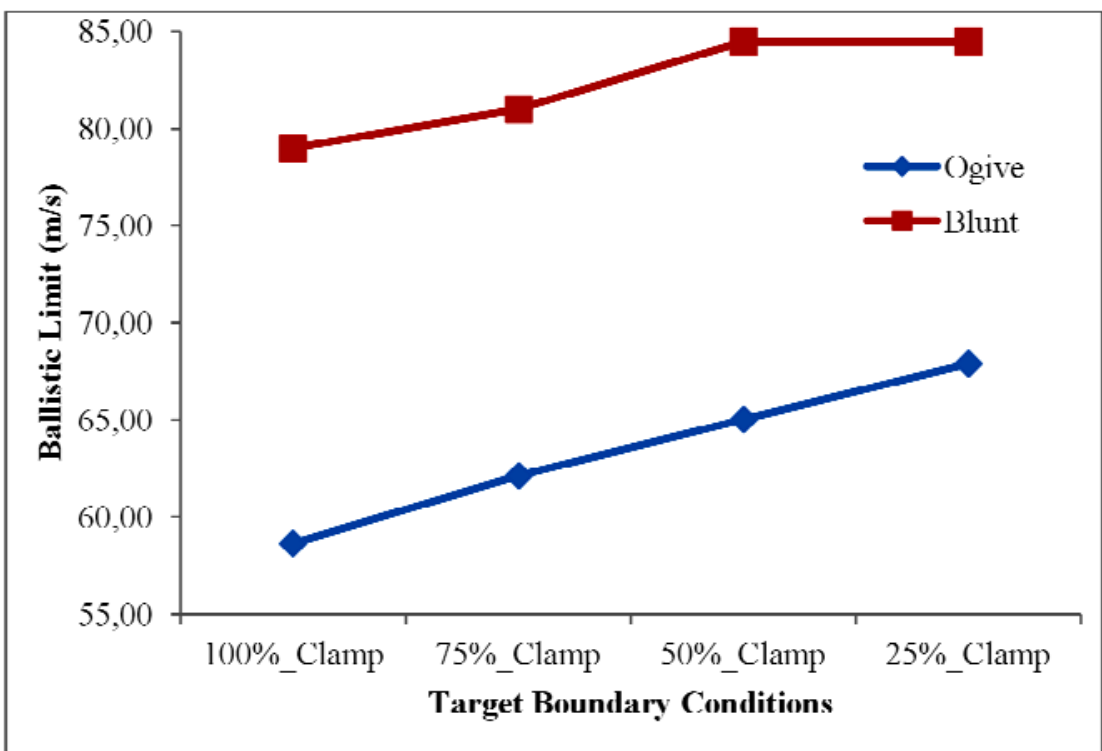

Fig.12. Variation of ballistic limit with the target boundary condition.
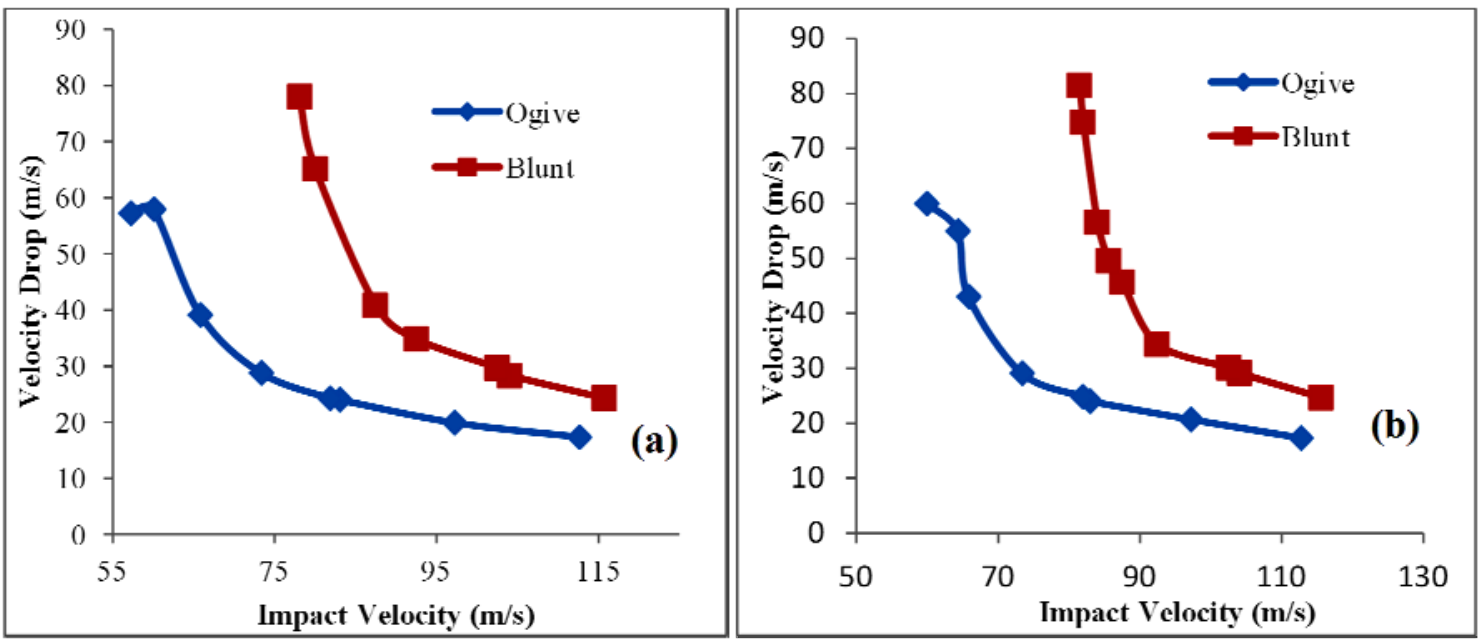

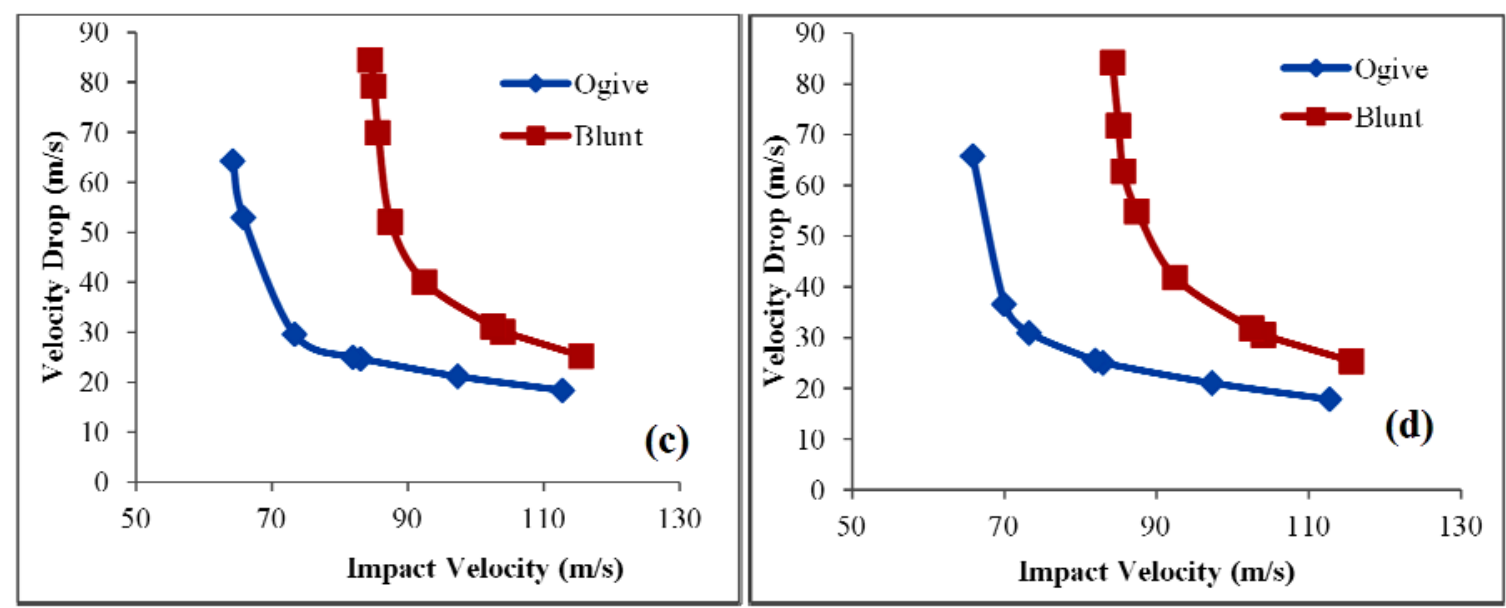

Fig.13. Comparison of velocity drop of blunt and ogive nosed projectiles impacted on $1 \mathrm{~mm}$ thick monolithic target with periphery boundary conditions of (a) $100 \%$ clamp (b) $75 \%$ clamp (c) $50 \%$ clamp (d) $25 \%$ clamp.

Figure 14 shows the variation in velocity drop with boundary condition. For same impact velocity the velocity drop was highest for $25 \%$ clamped periphery followed by $50 \%, 75 \%$ and $100 \%$ clamped periphery target plate. Although at high impact velocity this difference becomes insignificant for both the projectiles. Figure 15 shows the comparison of energy consumption of the target subjected to ogival and blunt projectile impact. It was observed that the energy absorbed by the target was higher for blunt nosed projectile compared to ogival projectile impact for each case. Again it decreases with an increase in impact velocity. Figure 16 shows the variation in energy consumption with boundary condition. It can be observed that the energy consumption by the target plate decreases with an increase in impact velocity for both the projectile impact.
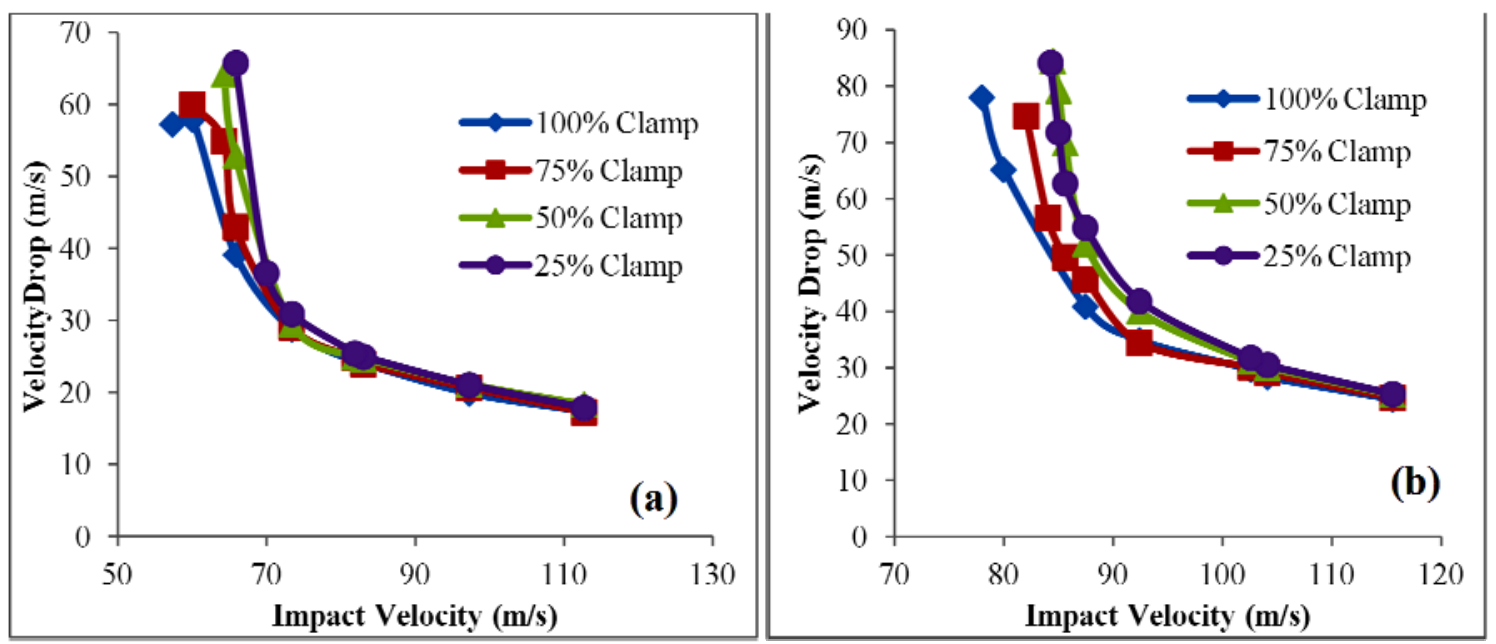

Fig.14. Variation in velocity drop for different boundary condition for (a) ogive nosed (b) blunt nosed projectile impact. 

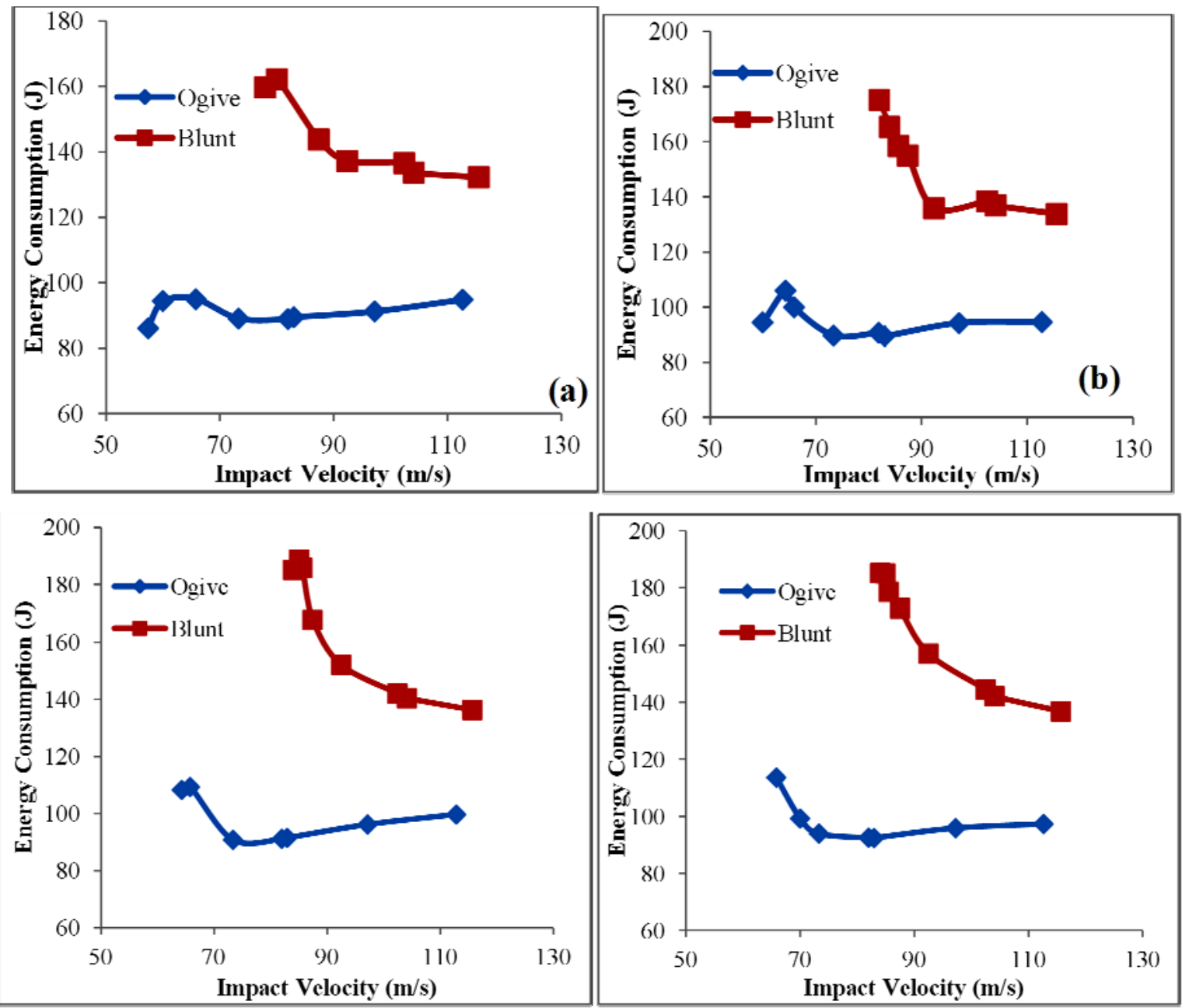

(c)

(d)

Fig.15. Comparison of energy absorbtion of blunt and ogive nosed projectiles for different target boundary conditions (a) $100 \%$ clamp (b) $75 \%$ clamp (c) $50 \%$ clamp (d) $25 \%$ clamp.
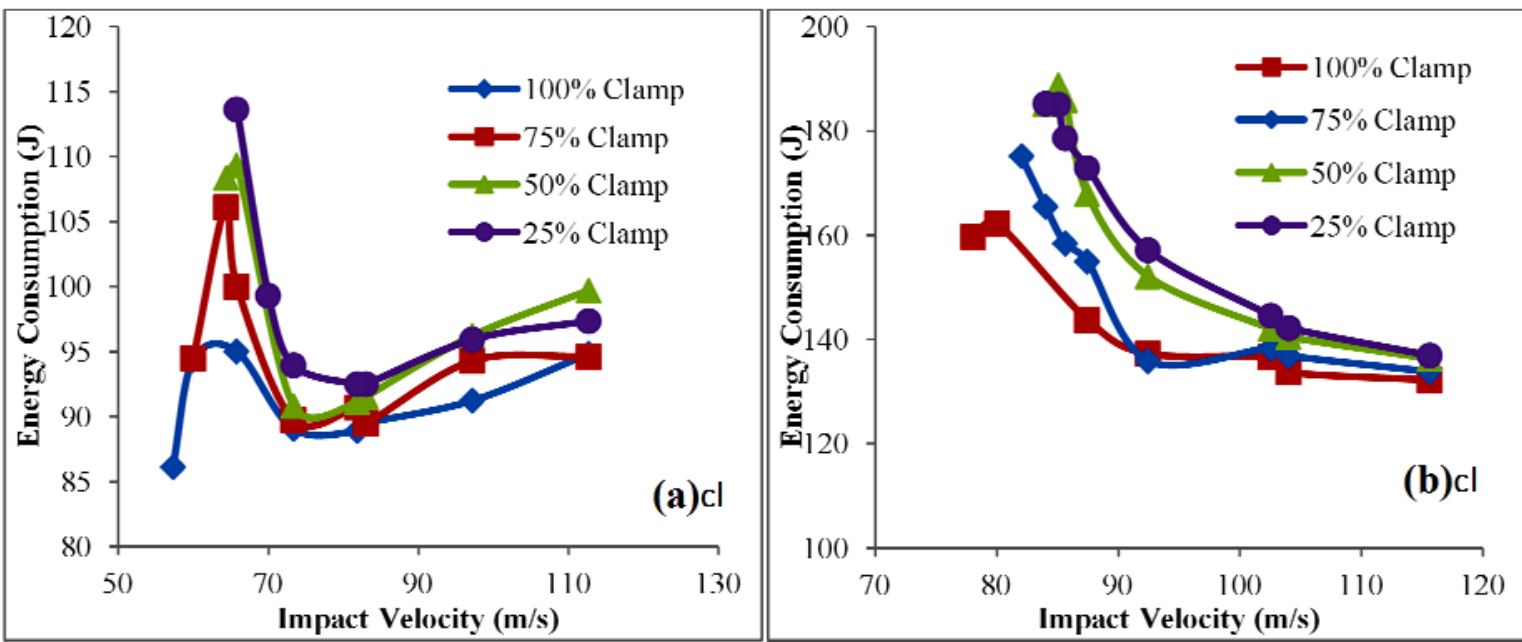

Fig.16. Variation in energy consumption for different boundary conditions for (a) ogive nosed (b) blunt nosed projectile impact. 


\section{Conclusions}

Three-dimensional numerical simulations were performed wherein ogive and blunt nosed projectiles were hit normally on $1 \mathrm{~mm}$ thick $1100-\mathrm{H} 12$ aluminum target with varying periphery boundary conditions keeping span diameter constant as $255 \mathrm{~mm}$.

For ogive nosed projectile the increase in the ballistic limit of $75 \%$ clamped, $50 \%$ clamped and $25 \%$ clamped target was found to be $5.9 \%, 10.8 \%$ and $15.7 \%$ higher than the $100 \%$ clamp target respectively. The ballistic limit of $75 \%$ clamped target was found to be $4.4 \%$ and $8.4 \%$ lower than $50 \%$ and $25 \%$ clamped boundary condition. Whereas the ballistic limit of $25 \%$ clamped boundary condition was found to be $4.4 \%$ higher than the $50 \%$ clamped boundary condition.

For blunt nosed projectile the increase in the ballistic limit of $75 \%$ clamped, $50 \%$ clamped and $25 \%$ clamped target was found to be $2.5 \%, 6.9 \%$ and $6.6 \%$ higher than the $100 \%$ clamped target respectively. The ballistic limit of $75 \%$ clamped target was found to be $4.1 \%$ and $3.8 \%$ lower than $50 \%$ and $25 \%$ clamped boundary condition. Whereas the ballistic limit of $25 \%$ clamped boundary condition was found to be $0.29 \%$ lower than the $50 \%$ clamp boundary condition. The variation of boundary condition had a significant effect on the ballistic limit for both the projectile cases.

The ballistic limit velocity of both the projectiles consistently increased with an increase in the unclamped periphery region. The increase in the ballistic limit occurred due to the increase in plastic deformation of the target.

\section{Nomenclature}

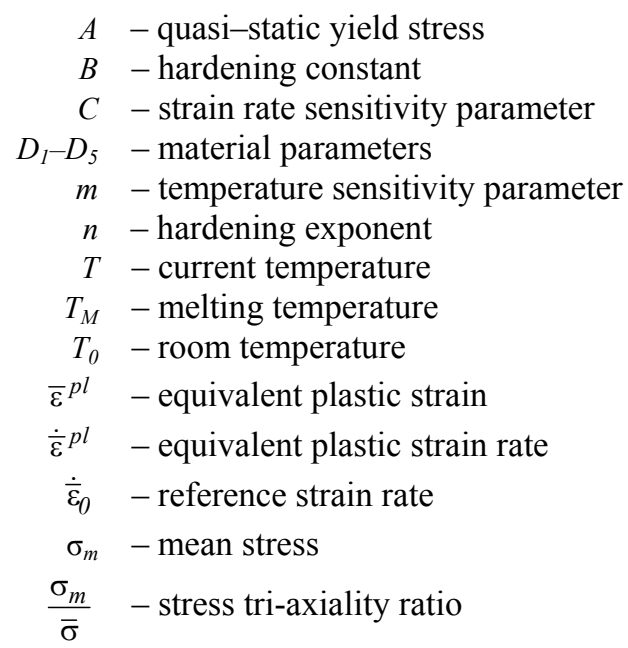

\section{References}

ABAQUS/Explicit user's manual. Version 6.7: vol.1(2), 2007.

Arias A., Rodr1'guez-Martı'nez J.A. and Rusinek A. (2008): Numerical simulations of impact behavior of thin steelplates subjected to cylindrical, conical and hemispherical non-deformable projectiles. - Engineering Fracture Mechanics, vol.75, pp.1635-1656.

Børvik T., Clausen A.H., Hopperstad O.S. and Langseth M. (2002): Perforation of $12 \mathrm{~mm}$ thick steel plates by $20 \mathrm{~mm}$ diameter projectiles with flat, hemispherical and conical noses, Part II: numerical simulations. - International Journal of Impact Engineering, vol.27, pp.37-64. 
Børvik T., Forrestal M.J., Hopperstad O.S., Warren T.L. and Langseth M. (2009): Perforation of AA5083-H116 aluminium plates with conical-nose steel projectiles-calculations. - International Journal of Impact Engineering, vol.36, pp.426-437.

Børvik T., Leinum J.R., Solberg J.K., Hopperstad O.S. and Langseth M. (2001): Observations on shear plug formation in Weldox 460 E steel plates impacted by blunt-nosed projectiles. - International Journal of Impact Engineering, vol.25, pp.553-572.

Corran R.S.J., Shadbolt P.J. and Ruiz C. (1983): Impact loading of plates - an experimental investigation. - Int. J. Impact Eng., vol.1(1), pp.3-22.

Dean J., Dunleavy C.S., Brown P.M. and Clyne T.W. (2009): Energy absorption during projectile perforation of thin steel plates and the kinetic energy of ejected fragments. - International Journal of Impact Engineering, vol.36, pp.1250-1258.

Gupta N.K., Iqbal M.A. and Sekhon G.S. (2006): Experimental and numerical studies on the behavior of thin aluminum plates subjected to impact by blunt- and hemispherical-nosed projectiles. - Int. J. Impact Engng., vol.32, pp.19211944.

Gupta N.K., Iqbal M.A. and Sekhon G.S. (2007): Effect of projectile nose shape, impact velocity and target thickness on deformation behavior of aluminum plates. - Int. J. Solids and Structure, vol.44, pp.3411-3439.

Iqbal M.A., Chakrabarti A., Beniwal S. and Gupta N.K. (2010): 3D numerical simulations of sharp nosed projectile impact on ductile targets. - International Journal of Impact Engineering, vol.37, pp.185-195.

Iqbal M.A., Gupta G., Diwakar A., and Gupta N.K. (2010): Effect of projectile nose shape on the ballistic resistance of ductile targets. - European Journal of Mechanics A/Solids,vol.29, pp.683-694.

Iqbal M.A., Gupta P.K., Deore V.S., Tak S.K. Tiwari G. and Gupta N.K. (2012): Effect of target span and configuration on the ballistic limit. - International Journal of Impact Engineering, vol.42, pp.11-24.

Johnson G.R. and Cook W.H. (1983): A constitutive model and data for metals subjected to large strains, high strain rates and high temperatures. - Proc. the Seventh International Symposium on Ballistics, The Hague.

Johnson G.R. and Cook W.H. (1985): Fracture characteristics of three metals subjected to various strains, strain rates, temperatures and pressures. - Eng. Fract. Mech. vol.21(1), pp.31-48.

Rusinek A., Rodrı'guez-Martı'nez J.A., Arias A., Klepaczko J.R. and Puente J.L. (2008): Influence of conical projectile diameter on perpendicular impact of thin steel plate. - Engineering Fracture Mechanics, vol.75, pp.2946-2967.

Received: August 29, 2013

Revised: October 9, 2013 